\title{
Hyperventilation as one of the mechanisms of persistent dyspnoea in SARS-CoV-2 survivors
}

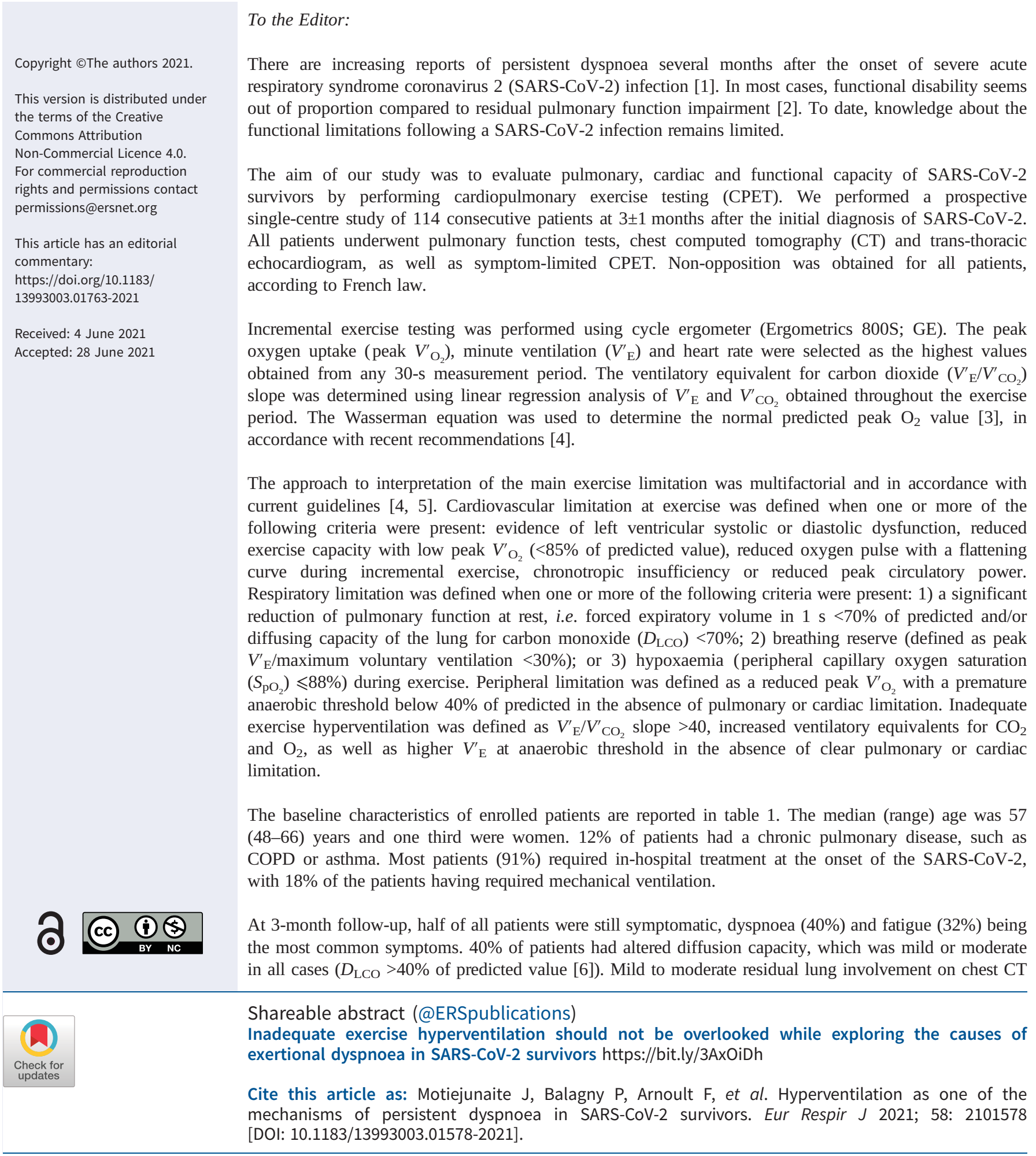


TABLE 1 Characteristics of SARS-CoV-2 infected patients at 3-month follow-up and results of pulmonary function tests, echocardiography and cardiopulmonary exercise testing (CPET) according to diffusion capacity of the lung for carbon monoxide ( $\left.D_{\text {LCo }}\right)$

\begin{tabular}{|c|c|c|c|c|}
\hline & All patients $(n=114)$ & $D_{\text {LCO }}>75 \%(n=63)$ & $D_{\text {LCO }} \leqslant 75 \%(n=48)$ & $\mathrm{p}$-value \\
\hline Age, years & $57(48-66)$ & $55(47-67)$ & $59(48-66)$ & 0.509 \\
\hline Female sex & $38(33 \%)$ & $25(40 \%)$ & $10(21 \%)$ & 0.073 \\
\hline $\mathrm{BMI}, \mathrm{kg} \cdot \mathrm{m}^{-2}$ & $27.8(24.2-30.1)$ & $26.2(24.6-30.9)$ & $27.3(24.2-30.6)$ & 0.853 \\
\hline \multicolumn{5}{|l|}{ Comorbidities } \\
\hline Hypertension & $49(43 \%)$ & $27(43 \%)$ & $23(48 \%)$ & 0.529 \\
\hline Obesity $\left(\mathrm{BMI}>30 \mathrm{~kg} \cdot \mathrm{m}^{-2}\right)$ & $34(30 \%)$ & $20(32 \%)$ & $14(29 \%)$ & 1 \\
\hline Diabetes & $25(22 \%)$ & $13(21 \%)$ & $13(27 \%)$ & 0.234 \\
\hline COPD/asthma & $14(12 \%)$ & $4(6 \%)$ & $10(21 \%)$ & 0.049 \\
\hline Sleep apnoea & $11(10 \%)$ & $5(8 \%)$ & $5(10 \%)$ & 0.682 \\
\hline Coronary artery disease & $6(5 \%)$ & $3(5 \%)$ & $3(6 \%)$ & 1 \\
\hline Smoking status & & & & 0.102 \\
\hline Never & $80(70 \%)$ & $49(78 \%)$ & $29(60 \%)$ & \\
\hline Former & $31(27 \%)$ & $12(19 \%)$ & $18(38 \%)$ & \\
\hline Active & $3(3 \%)$ & $2(3 \%)$ & $1(2 \%)$ & \\
\hline \multicolumn{5}{|l|}{ Initial COVID-19 management } \\
\hline Conventional hospitalisation & $104(91 \%)$ & $59(87 \%)$ & $45(96 \%)$ & 0.115 \\
\hline Severe form (requiring $>6 \mathrm{~L}$ of $\mathrm{O}_{2}$ ) & $56(49 \%)$ & $26(41 \%)$ & $31(66 \%)$ & 0.071 \\
\hline ICU stay & $25(22 \%)$ & $9(14 \%)$ & $17(35 \%)$ & 0.017 \\
\hline Endotracheal intubation with mechanical ventilation & $21(18 \%)$ & $8(13 \%)$ & $13(27 \%)$ & 0.162 \\
\hline Hospital length of stay, days & $10(6-18)$ & $9(5-14)$ & $12(8-24)$ & 0.019 \\
\hline Administration of high-dose steroids & $54(47 \%)$ & $26(41 \%)$ & $28(58 \%)$ & 0.112 \\
\hline Degree of initial lung involvement & & & & 0.183 \\
\hline$<25 \%$ & $28(36 \%)$ & $17(38 \%)$ & $11(31 \%)$ & \\
\hline $25-50 \%$ & $36(45 \%)$ & $23(52 \%)$ & $13(36 \%)$ & \\
\hline $50-75 \%$ & $14(18 \%)$ & $3(6 \%)$ & $11(31 \%)$ & \\
\hline$\geqslant 75 \%$ & $3(3 \%)$ & $2(4 \%)$ & $1(2 \%)$ & \\
\hline \multicolumn{5}{|l|}{ Persistent symptoms at 3 months follow-up } \\
\hline Any persistent symptom & $58(51 \%)$ & $34(51 \%)$ & $24(51 \%)$ & 0.23 \\
\hline Dyspnoea & $45(40 \%)$ & $21(33 \%)$ & $23(48 \%)$ & 0.147 \\
\hline Fatigue & $36(32 \%)$ & $17(27 \%)$ & $19(40 \%)$ & 0.259 \\
\hline Cough & $16(14 \%)$ & $6(9 \%)$ & $10(21 \%)$ & 0.095 \\
\hline Chest pain & $7(6 \%)$ & $7(12)$ & $0(0 \%)$ & 0.045 \\
\hline \multicolumn{5}{|l|}{ Pulmonary function tests } \\
\hline VC \% pred & $90(78-105)$ & $94(83-106)$ & $81(72-102)$ & 0.004 \\
\hline $\mathrm{FEV}_{1} \%$ pred & $93(81-102)$ & $97(84-108)$ & $83(72-96)$ & $<0.001$ \\
\hline $\mathrm{FEV}_{1} / \mathrm{VC}$ & $0.81(0.74-0.86)$ & $0.81(0.78-0.86)$ & $0.81(0.72-0.86)$ & 0.128 \\
\hline TLC \% pred & $92(77-105)$ & $96(85-108)$ & $82(73-97)$ & $<0.001$ \\
\hline$D_{\text {LCO }} \%$ pred & $79(65-90)$ & $88(82-97)$ & $64(55-70)$ & $<0.001$ \\
\hline$K_{\mathrm{co}} \%$ pred & $92(82-106)$ & $102(90-115)$ & $84(74-93)$ & $<0.001$ \\
\hline Degree of residual lung involvement on CT & & & & 0.018 \\
\hline Absent & $40(35 \%)$ & $28(47 \%)$ & $11(25 \%)$ & \\
\hline$<10 \%$ & $40(35 \%)$ & $23(39 \%)$ & $16(36 \%)$ & \\
\hline $10-25 \%$ & $20(18 \%)$ & $6(11 \%)$ & $14(32 \%)$ & \\
\hline $25-50 \%$ & $5(4 \%)$ & $2(3 \%)$ & $3(7 \%)$ & \\
\hline \multicolumn{5}{|l|}{ Echocardiography } \\
\hline Left ventricular ejection fraction, $\%$ & $65(60-68)$ & $64(61-68)$ & $65(56-71)$ & 0.78 \\
\hline Left ventricular global longitudinal strain & $18(16-20)$ & $19(17-20)$ & $17(14-19)$ & 0.017 \\
\hline Systolic pulmonary artery pressure, $\mathrm{mmHg}$ & $27(23-30)$ & $27(23-30)$ & $27(24-30)$ & 0.896 \\
\hline \multicolumn{5}{|l|}{ Cardiopulmonary exercise testing } \\
\hline Time from hospital discharge to CPET, days & $90(71-106)$ & $90(76-109)$ & $87(69-100)$ & 0.089 \\
\hline Load reached, W & $112(73-144)$ & $124(97-149)$ & $98(83-136)$ & 0.021 \\
\hline$\%$ of target heart rate & $86(80-95)$ & $90(82-98)$ & $82(72-91)$ & 0.003 \\
\hline$V^{\prime}{ }_{\mathrm{O}_{2}} / \mathrm{W}$ slope & $9.34(8.00-10.41)$ & $9.34(8.16-10.47)$ & $9.30(7.91-10.04)$ & 0.373 \\
\hline Peak respiratory exchange ratio & $1.19(1.15-1.26)$ & $1.18(1.13-1.26)$ & $1.20(1.16-1.27)$ & 0.174 \\
\hline Respiratory rate at peak exercise & $37(32-43)$ & $37(32-44)$ & $37(33-43)$ & 0.891 \\
\hline Breathing reserve, $\%$ & $43(29-54)$ & $38(28-50)$ & $47(39-58)$ & 0.008 \\
\hline$V^{\prime}{ }_{\mathrm{O}_{2}}$ at anaerobic threshold, $\mathrm{mL} \cdot \mathrm{kg}^{-1} \cdot \mathrm{min}^{-1}$ & $10.3(8.8-12.3)$ & $10.9(9.1-12.8)$ & $9.8(8.6-11.6)$ & 0.075 \\
\hline$V_{\mathrm{O}_{2}}^{\prime}$ at anaerobic threshold, $\%$ pred & $43(34-51)$ & $45(38-53)$ & $39(33-49)$ & 0.014 \\
\hline
\end{tabular}


TABLE 1 Continued

\begin{tabular}{|c|c|c|c|c|}
\hline & All patients $(n=114)$ & $D_{\text {LCO }}>75 \%(n=63)$ & $D_{\text {LCO }} \leqslant 75 \%(n=48)$ & p-value \\
\hline Patients with predicted $V^{\prime} \mathrm{O}_{2}$ at anaerobic threshold $<40 \%$ & $49(43 \%)$ & $21(33 \%)$ & $28(58 \%)$ & 0.009 \\
\hline$V_{\mathrm{O}_{2}}^{\prime}$ peak, $\mathrm{mL} \cdot \mathrm{kg}^{-1} \cdot \mathrm{min}^{-1}$ & $17.9(14.7-20.6)$ & $19.0(16.0-23.4)$ & $16.2(13.8-18.9)$ & 0.002 \\
\hline$V_{\mathrm{O}_{2}}^{\prime}$ peak, $\%$ pred & $71(60-85)$ & $79(64-87)$ & $62(55-76)$ & $<0.001$ \\
\hline Patients with predicted $V_{\mathrm{O}_{2}}^{\prime}<85 \%$ & $85(75 \%)$ & $43(68 \%)$ & $41(85 \%)$ & 0.034 \\
\hline Peak circulatory power & $3112(2268-3726)$ & $3245(2455-3861)$ & $2771(1994-3459)$ & 0.018 \\
\hline Peak oxygen pulse, $\mathrm{mL}$ per beat & $10.4(8.1-12.4)$ & $10.6(8.4-12.5)$ & $9.7(7.6-12.2)$ & 0.506 \\
\hline$\%$ of theoretical peak oxygen pulse & $79(66-93)$ & $81(70-93)$ & $78(64-87)$ & 0.12 \\
\hline$\Delta$ oxygen pulse between rest and peak exercise, $\mathrm{mL}$ per beat & $5.5(4.1-7.7)$ & $5.7(4.2-7.9)$ & $5.4(3.9-7.4)$ & 0.286 \\
\hline$V_{E}^{\prime}$ at anaerobic threshold, $L \cdot \mathrm{min}^{-1}$ & $27(20-36)$ & $28(20-38)$ & $28(23-33)$ & 0.964 \\
\hline$V_{E}^{\prime}$ at peak exercise, $L \cdot \mathrm{min}^{-1}$ & $61(45-77)$ & $67(44-79)$ & $56(45-71)$ & 0.184 \\
\hline$V_{E}^{\prime} / \mathrm{MVV}$ at anaerobic threshold & $0.28(0.22-0.38)$ & $0.27(0.22-0.33)$ & $0.30(0.23-0.44)$ & 0.167 \\
\hline$V_{E}^{\prime} / M V V$ at peak exercise & $0.64(0.52-0.78)$ & $0.64(0.54-0.76)$ & $0.64(0.51-0.77)$ & 0.458 \\
\hline$V_{\mathrm{E}}^{\prime} / V_{\mathrm{CO}_{2}}^{\prime}$ ratio at anaerobic threshold & $30(27-33)$ & $30(27-32)$ & $31(26-34)$ & 0.178 \\
\hline$V_{\mathrm{E}}^{\prime} / V_{\mathrm{CO}_{2}}^{\prime}$ ratio at peak exercise & $36(32-39)$ & $35(32-37)$ & $37(35-43)$ & 0.021 \\
\hline$V_{\mathrm{E}}^{\prime} / V^{\prime} \mathrm{CO}_{2}$ slope & $33(30-38)$ & $32(30-36)$ & $34(30-40)$ & 0.105 \\
\hline Elevated $V_{E}^{\prime} / V_{\mathrm{CO}_{2}}$ slope $>35$ & $37(32 \%)$ & $17(27 \%)$ & $19(40 \%)$ & 0.177 \\
\hline Presence of inappropriate hyperventilation & $27(24 \%)$ & $11(18 \%)$ & $15(31 \%)$ & 0.141 \\
\hline Limitation at exercise & & & & 0.051 \\
\hline No limitation & $40(35 \%)$ & $29(46 \%)$ & $10(21 \%)$ & \\
\hline Muscular deconditioning & $51(45 \%)$ & $22(35 \%)$ & $28(58 \%)$ & \\
\hline Cardiovascular & 0 & 0 & 0 & \\
\hline Pulmonary & $1(1 \%)$ & 0 & $1(2 \%)$ & \\
\hline Exercise hyperventilation & $19(16 \%)$ & $9(14 \%)$ & $8(19 \%)$ & \\
\hline Lack of motivation & $3(3 \%)$ & $2(3 \%)$ & $1(2 \%)$ & \\
\hline
\end{tabular}

Values are presented as median (interquartile range) for quantitative variables and as $\mathrm{n}(\%)$ for qualitative variables. Comparisons between groups were performed with unpaired t-tests for normally distributed continuous variables and Mann-Whitney U-tests for non-normally distributed continuous variables. Chi-squared test of independence was used to test the distribution categorical variables. $D_{\text {Lco }}$ measurements were available in 111 patients. BMI: body mass index; COVID-19: coronavirus disease 2019; SARS-CoV-2: severe acute respiratory syndrome coronavirus 2; ICU: intensive care unit; VC: vital capacity; $\mathrm{FEV}_{1}$ : forced expiratory volume in $1 \mathrm{~s}$; TLC: total lung capacity; $K_{\mathrm{CO}}$ : carbon monoxide transfer coefficient; $\mathrm{CT}$ : computed tomography; $V_{\mathrm{O}_{2}}^{\prime}$ : oxygen uptake; $V^{\prime}{ }_{\mathrm{E}} / V^{\prime} \mathrm{CO}_{2}$ : ventilatory equivalent for carbon dioxide; $V_{\mathrm{E}}^{\prime}$ : minute ventilation; $V^{\prime} \mathrm{CO}_{2}$ : carbon dioxide production; MVV: maximal voluntary ventilation.

was found in $65 \%$ of patients. Trans-thoracic echocardiogram showed a normal left ventricular ejection fraction in the majority of the patients as well as a preserved global longitudinal strain. Pulmonary hypertension (systolic pulmonary artery pressure (sPAP) $>40 \mathrm{mmHg}$ ) was detected in one patient.

During CPET, $75 \%$ of patients had exercise impairment with peak $V_{\mathrm{O}_{2}}^{\prime}$ values $<85 \%$ of predicted. The median (range) peak $V_{\mathrm{O}_{2}}^{\prime}$ was $17.9(14.7-20.6) \mathrm{mL} \cdot \mathrm{kg}^{-1} \cdot \mathrm{min}^{-1}$. Peripheral deconditioning was the main limiting factor in $43 \%$ of patients. $24 \%$ of patients had an elevated $V^{\prime}{ }_{E} / V^{\prime} \mathrm{CO}_{2}$ ratio at peak exercise $(>40)$ and $32 \%$ had an elevated $V^{\prime}{ }_{E} / V^{\prime} \mathrm{CO}_{2}$ slope $(>35)$. Exercise hyperventilation was the main limitation in $16 \%$ of patients. After adjustment for covariates, age $(\beta=0.4, \mathrm{p}=0.002)$, intensive care stay $(\beta=-10.27, \mathrm{p}=0.017)$, mechanical ventilation $(\beta=-12.63, p=0.004)$ and length of hospital stay $(\beta=-0.24, p=0.009)$ were independently associated with \% predicted peak $V_{\mathrm{O}_{2}}^{\prime}$.

Patients who had altered diffusion capacity $\left(D_{\text {LCO }} \leqslant 75 \%\right)$ reached a lower maximal load and had lower peak $V_{\mathrm{O}_{2}}^{\prime}$ values at anaerobic threshold as well as at peak exercise. However, the prevalence of hyperventilation was similar in both groups. Interestingly, patients with reduced $D_{\text {LCO }}$ did not report more persistent dyspnoea.

The prevalence of exercise limitation in our cohort was much higher than in a study by RiNALDo et al. [7]. In accordance with a previous report [7], reduced exercise capacity in our cohort was mostly due to peripheral deconditioning. However, our study also found an elevated $V^{\prime}{ }_{E} / V^{\prime} \mathrm{CO}_{2}$ slope in one third of the study participants, suggesting a high incidence of inadequate exercise hyperventilation. Our findings are supported by two previous studies [8,9] which reported persistent ventilatory inefficiency in smaller cohorts of SARS-CoV-2 survivors who underwent CPET. Increased $V^{\prime}{ }_{E} / V_{\mathrm{CO}_{2}}^{\prime}$ slope and reduced diffusion capacity might suggest pulmonary hypertension at exercise [10]. However, in our cohort only one patient had an elevated sPAP at rest. What is more, there was no statistically significant difference in $V^{\prime}{ }_{E} / V^{\prime} \mathrm{CO}_{2}$ according to $D_{\text {LCO }}$ subgroups. 
Exercise hyperventilation is a condition characterised by alveolar hyperventilation that is inappropriate considering metabolic needs and mechanical stress in the body [11]. The origin of this hyperventilation is unknown but may be related to an abnormality of central ventilatory control in the aftermath of pulmonary infection [12]. Increased output of the respiratory centre results in respiratory alkalosis [12], which in turn activates the autonomous nervous system, causing a variety of neurovegetative symptoms as well as arterial vasoconstriction and hypoperfusion [13]. The diagnosis of hyperventilation syndrome is usually established after exclusion of other cardiopulmonary diseases, such as heart failure, asthma or COPD. CPET is useful for the differential diagnosis of dyspnoea at exertion. Markers of hyperventilation include increased $V^{\prime}{ }_{\mathrm{E}}^{\prime}$ $V^{\prime} \mathrm{CO}_{2}$ ratio and slope during exercise $[14,15]$, rapid increase in ventilatory equivalents for $V_{\mathrm{O}_{2}}^{\prime}$ and $V^{\prime} \mathrm{CO}_{2}$, abnormally high respiratory rate, and higher $V^{\prime}{ }_{E}$ at anaerobic threshold [4]. Hyperventilation-related symptoms can range from dyspnoea, palpitations and chest pain, to dizziness and fatigue, which have been reported by the so-called "Covid long-haulers" [1]. Identification of hyperventilation syndrome is important, because the variety of disabling symptoms might take SARS-CoV-2 survivors to a wide range of specialist consultations, numerous investigations and inappropriate treatment, whereas respiratory physiotherapy with an experienced therapist with a focus on patient education can help significantly. Spontaneous recovery is also possible.

Our study has several limitations. Firstly, several parameters that could be of interest, such as end-tidal carbon dioxide tension and individual $S_{\mathrm{pO}_{2}}$ data, were unavailable for statistical analysis. However, none of the patients desaturated at exercise. Moreover, the limitations of reference values for CPET must be taken into account, as \% of predicted values are less accurate for obese patients. However, the reference values that were used are in accordance with international guidelines. Another limitation of the study is the absence of arterial blood gas measurement, which could confirm the presence of respiratory alkalosis and thus further strengthen the diagnosis of hyperventilation syndrome. The noninvasive assessment of pulmonary gas exchange during exercise is less reliable and is known to produce higher values of ventilatory equivalents in patients without significant lung disease.

In conclusion, our study confirmed that peripheral deconditioning is the main mechanism of exercise intolerance in the aftermath of SARS-CoV-2. However, exercise hyperventilation should not be overlooked while exploring the causes of dyspnoea in SARS-CoV-2 survivors.

Justina Motiejunaite $\oplus^{1,2}$, Pauline Balagny ${ }^{1,3}$, Florence Arnoult ${ }^{1}$, Laurence Mangin ${ }^{1,4}$, Catherine Bancal ${ }^{1}$, Emmanuelle Vidal-Petiot ${ }^{1,2,5}$, Martin Flamant ${ }^{1,2,5}$, Guillaume Jondeau ${ }^{2,6,7}$, Alain Cohen-Solal ${ }^{2,8,9}$, Marie-Pia d'Ortho ${ }^{1,2,10}$ and Justine Frija-Masson $\oplus^{1,2,10}$

${ }^{1}$ Service de Physiologie Clinique-Explorations Fonctionnelles, Assistance Publique Hôpitaux de Paris, Hôpital Bichat-Claude Bernard, Paris, France. ${ }^{2}$ Université de Paris, Paris, France. ${ }^{3}$ INSERM, Populationbased Epidemiological Cohorts Unit, UMS 011, Paris, France. ${ }^{4}$ Laboratoire Matière et Système Complexes UMR 7057, CNRS, Paris, France. ${ }^{5}$ INSERM, U1149, Paris, France. ${ }^{6}$ Service de Cardiologie, Assistance Publique Hôpitaux de Paris, Hôpital Bichat-Claude Bernard, Paris, France. ${ }^{7}$ INSERM, U1148, Paris, France. ${ }^{8}$ Service de Cardiologie, Assistance Publique Hôpitaux de Paris, Hôpital Lariboisière, Paris, France. ${ }^{9}$ INSERM UMR-S 942, Paris, France. ${ }^{10}$ INSERM, UMR 1141 NeuroDiderot, Paris, France.

Corresponding author: Justina Motiejunaite (justina.motiejunaite@aphp.fr)

Author contributions: J. Motiejunaite, P. Balagny, F. Arnoult, L. Mangin, C. Bancal and J. Frija-Masson performed the cardiopulmonary function tests. J. Motiejunaite and P. Balagny performed a literature review and the statistical analysis. J. Motiejunaite, E. Vidal-Petiot and M. Flamant performed data collection and database management. J. Motiejunaite and J. Frija-Masson drafted the manuscript. P. Balagny, F. Arnoult, L. Mangin, C. Bancal, E. Vidal-Petiot, M. Flamant, G. Jondeau, A. Cohen-Solal and M-P. d'Ortho contributed significantly to manuscript correction and finalisation. All authors contributed to the article and approved the submitted version.

Conflict of interest: E. Vidal-Petiot reports personal fees and non-financial support from Servier, outside the submitted work. A. Cohen-Solal has received grants or honoraria from Novartis, Servier, Daiichi Sankyo, Vifor, Menarini and Cardiorentis, outside of the submitted work. J. Frija-Masson reports non-financial support from Vitalaire, Boehringer Ingelheim, Oxyvie and LVL Medical, outside the submitted work. All other authors declare that the research was conducted in the absence of any commercial or financial relationships that could be construed as a potential conflict of interest. 
References

1 Carfi A, Bernabei R, Landi F, et al. Persistent symptoms in patients after acute COVID-19. JAMA 2020; 324: 603-605.

2 Frija-Masson J, Debray M-P, Boussouar S, et al. Residual ground glass opacities three months after Covid-19 pneumonia correlate to alteration of respiratory function: the post Covid M3 study. J Respir Med 2021; 184: 106435.

3 Wasserman KHJ, Sue DY, Casaburi R, et al. Principles of Exercise Testing and Interpretation: Including Pathophysiology and Clinical Applications. 3rd edition. Philadelphia, Lippincott, Williams \& Wilkins, 1999.

4 American Thoracic Society, American College of Chest Physicians. ATS/ACCP Statement on cardiopulmonary exercise testing. Am J Respir Crit Care Med 2003; 167: 211-277.

5 Radtke T, Crook S, Kaltsakas G, et al. ERS statement on standardisation of cardiopulmonary exercise testing in chronic lung diseases. Eur Respir Rev 2019; 28: 180101.

6 Pellegrino R, Viegi G, Brusasco V, et al. Interpretative strategies for lung function tests. Eur Respir J 2005; 26: 948-968.

7 Rinaldo RF, Mondoni M, Parazzini EM, et al. Deconditioning as main mechanism of impaired exercise response in COVID-19 survivors. Eur Respir J 2021; 58: 2100870.

8 Dorelli G, Braggio M, Gabbiani D, et al. Importance of cardiopulmonary exercise testing amongst subjects recovering from COVID-19. Diagnostics 2021; 11: 507.

9 Debeaumont D, Boujibar F, Ferrand-Devouge E, et al. Cardiopulmonary exercise testing to assess persistent symptoms at 6 months in people with COVID-19 who survived hospitalization - a pilot study. Phys Ther 2021; 101: pzab099.

10 Oliveira RKF, Waxman $\mathrm{AB}$, Hoover $\mathrm{PJ}$, et al. Pulmonary vascular and right ventricular burden during exercise in interstitial lung disease. Chest 2020; 158: 350-358.

11 Gardner WN. Hyperventilation: Diagnosis and Therapy. In: Beverly H, Timmons RL, eds. Behavioral and Psychological Approaches to Breathing Disorders. New York, Springer Science+Business Media, LLC, 1994, 99-111.

12 Jack S, Rossiter HB, Warburton CJ, et al. Behavioral influences and physiological indices of ventilatory control in subjects with idiopathic hyperventilation. Behav Modif 2003; 27: 637-652.

13 Motiejunaite J, Balagny P, Arnoult F, et al. Hyperventilation: a possible explanation for long-lasting exercise intolerance in mild COVID-19 survivors? Front Physiol 2020; 11: 614590.

14 Brat K, Stastna N, Merta Z, et al. Cardiopulmonary exercise testing for identification of patients with hyperventilation syndrome. PLOS ONE 2019; 14: e0215997.

15 Balady GJ, Arena R, Sietsema K, et al. Clinician's guide to cardiopulmonary exercise testing in adults: a scientific statement from the American Heart Association. Circulation 2010; 122: 191-225. 